\title{
Issues in clinical practice in a South Asian Muslim community
}

\author{
A. Jawad Sheikh and Saeed Farooq
}

\begin{abstract}
The bulk of transcultural research has concentrated on particular themes, which include parasuicides among Bittish Asian women, schizophrenia among Afro-Cambeans, and clinical presentation of somatisation in different races (Littlewood \& Lipsedge, 1989). The focus has largely been on clinical patterns of illness and the social determinant of distress as experienced by ethnic minortiles in the community remains largely neglected. An aftempt has been made, after two years experience of working in a Birmingham city catchment area with an Asian Muslim community, to highlight day to day cultural issues which directly or indirectty contribute to psychiatric morbidity.
\end{abstract}

Psychiatrists working in an area with a high density of ethnic minority population should strive to educate themselves about the cultural and sensitive issues of the particular community. An awareness of the basic values, belief systems and dilemmas faced by the ethnic minority population is of great importance in guiding a psychiatrist towards appropriate intervention and management.

The following factors were the most common cultural issues which needed to be resolved and understood in psychiatric assessment.

\section{The type of marriage}

Couples often have a wide difference in their ages. Typically, the men who come to this country to work in factories become relatively more prosperous, and return to their country to get younger brides. The younger bride is exposed, through the influence of the media and local host culture, to a more open way of life. This causes conflict, unhappiness and confusion about her role.

Polygyny is not uncommon. Although it is not legal to have a second wife in the United Kingdom, there are cases where men did not disclose the second marriage or brought their wives on other people's passports. These actions are not so much a deliberate flouting of the law but are due to inability to see them in any other context than that of the freedom to continue long-standing cultural customs and practices.
Couples we came across in this predicament either had no children or their wives were chronically ill, underlining the importance of fertile unions in their traditions. The step toward polygyny creates problems with the Home Office. the law, and the Department of Social Security. It would be naive and cruel to meet these dilemmas with simple approval or disapproval. The psychiatrist then is in a situation of treating a person experiencing an understandable, not readily resolvable conflict.

The third problem involves the deeply rooted but opposing traditions of mixed partners. Young patients were referred suffering from stress, torn between their love for the person they want to marry and their loyalty to their parents and families. Marriages across religious and racial boundaries cause immense difficulties for an individual. The loyalty to family is often overriding and as a consequence the individual suffers. Advice to 'decide what you want and get on with it' does not suffice in day to day practice. It causes more guilt and self-blame, leading to mental and emotional disturbance of a clinical severity as often, if not more often, than conformity. Sheikh \& Guest (1991) attempted to explore psychiatric and marital morbidity in mixed race couples. The females scored significantly higher on the General Health Questionnaire than the males, a factor not found in a non-mixed population. On the Maudsley Marital Questionnaire, there was a tendency towards poor marital and sexual relationships.

\section{The status of women}

There are two distinct, though related, aspects to this issue. One is cultural and the other religious. Many women originate from tightly knit village communities, in which the narrow confines of domesticity cause little frustration. Yet their existence seems paradoxical in a British, urbanised society. They experience more confusion when their men are free to go out, learn the language and wear local clothes, whereas most of them are expected to continue to live as they would have done in their country of 
origin. This creates stress, frustration and conflict in a woman socially isolated in a strange country, without the support of her family or village that she hails from. She becomes a prisoner of her new circumstances - in which she probably had a very little say in the first instance! There have been couples where men have not allowed their women even to go to evening classes to learn English, fearing their independence and justifying their decision with religion. The plight of women in such circumstances should not be wholly blamed on Islam, which advocates education and an independent role for women who seek it. Rather they are confused by conflicting role models, the status and apparent freedom of women raised in the west, their legitimate aspirations, the often defensively controlling behaviour of their husbands, themselves fearful of contamination by the host culture, and the real underlying and legitimate standards which are expectations of their culture and religion.

\section{The joint family system}

Families of more than ten often live in two or three bedroom accommodation. These are extended families. There may, for example, be three brothers, all married with their children, living in the same house. This inevitably creates conflict and stress as they compete for independence and space. Such families often also have their parents living with them. More often than not it is the parents of the man who live with the family. This is a cultural and religious obligation, but has inherent problems because of overcrowding, exacerbation of authority issues, and allocation of tasks within the household. This results in difficult marriages, lack of personal growth, poor attention to children and general unhappiness. It is not the joint family system which is at fault but the lack of space, so readily available back home, where even ordinary people enjoy large verandas, open fields and more spacious homes. The weather here also forces people to live indoors, in the same house, for longer times than they would back home.

\section{The new generation}

There are tremendous issues to be resolved between the older and younger generations. The new generation more often has a different perception of life, in their belief systems and values. They are trapped in a struggle between a Pakistani and a British identity, mastering two languages, and a battle to defend their religion and customs against prejudice and misunderstanding. The generation gap is more difficult to cope with by them than British families in similar circumstances. This includes the further education of girls, career aspirations of children and the opportunities to make independent decisions outside the families. There is some sense in the reluctance of the younger generation to use a local Asian counsellor, a mosque Imam or even an Asian psychiatrist to talk things through, as they may side with the parents, or appear to do so. Indeed, there have been times when young Asian people have requested to see a white psychiatrist rather than an Asian psychiatrist. If one does not spend time and effort trying to understand the predicament of the new generation, it is easy to adopt a superficial and unhelpful line of therapy. The question, 'Who am I?' is a constantly repeated theme. The search for a satisfying personal image and role is unanswered and the youth remains confused and puzzled by self-doubt.

Living with dual nationality, double values, two or three languages to master, and then having to be accepted by the local culture remains an uphill task for the new generation, leading to conflicts, stress, anxieties, antisocial behaviour, and probably psychiatric morbidity. Young people born in this country have their loyalties put on test when asked to accept an arranged marriage, and having acquiesced, find it leads only to unhappiness, difficulties in adjustments, a life of existence rather than enjoyment. These problems are exacerbated by lack of employment opportunities which affects immigrant youth more than their British contemporaries.

\section{The stigma of mental illness}

The complaints of stigma of mental illness remain universal, but the effect is felt more in a close-knit community. This results in deception, hiding the secret and being on guard not to let this problem out in the community. The stigma excludes the patients from services like day hospital, group work or family therapy. Admissions to a psychiatric hospital remain a challenge and require a lot of reassurance and explanation. When parents arrange the marriage of their boys or girls who have had serious mental illness without disclosing this to the other party, this leads to much friction, unhappiness and frequent divorce. This problem should be tackled more vigorously with education, through the community leaders, both at cultural centres and at mosques.

\section{Immigration dificulties}

Although the families may have lived in. Britain for more than three decades, their heart and spirit often still rests in their home country. The families remain split between the two nations, 
and the first generation tend to resolve this issue by marrying their children born in the UK to the children of their families born in their home country. On paper, a person born in this country and being British by citizenship should not have much difficulty in getting his wife from his parents' home country. But this is not in practice so easy. The immigration rules and screening process are complex and slow and it may take years before a couple are united or children can join their families, or elderly parents are allowed to come and stay with their children in this country.

Immense stress, intolerable suffering and unending yearning is experienced year after year by these individuals and their families. A significant part of our clinical work is to write letters, bringing home to the responsible authorities at the Home Office and in the country of origin, the stress and psychiatric morbidity caused directly by the delay in the immigration process. It seems unfair that a large majority have to suffer ostensibly because of the abuse of the immigration rules by a minority.

\section{The languages}

We have the advantage of speaking and understanding Urdu and Punjabi and the support of a community nurse who speaks the language and understands the culture. Language remains the key to understanding psychopathology, history taking and obtaining a sound clinical assessment. Without being able to express, understand, explain and feel for a person, it is not possible to make a reasonable formulation of the problem. Many cases are mistakenly diagnosed hysterical, hypochondriacal, or even psychotic. Because of language difficulties the patients are not offered group work, individual psychotherapy or even a day hospital where their needs are met. A separate day hospital for Asians is seen as politically incorrect or segregation, and in a mixed day hospital it is difficult to fulfil the needs of the patients who do not speak English. Even the service of interpreters who are not trained in mental health work is a second best and hardly meets the needs of the patients. Interpretation is subject to bias and impression. Only a training in the basic phenomenology of psychiatric disorders can properly overcome these prejudicing processes.

\section{The religion}

As the majority of patients in the catchment area belong to the religion of Islam, it is important to recognise the role of the faith in individuals' lives. To remain objective and treat each person as an individual always remains a challenge in the therapist's mind. One may disagree passionately with the rules and regulations imposed by the religion on the individual and the family, and even be tempted to formulate the stress and the psychiatric difficulties in the light of the dilemm a posed by the faith, but the therapist's professional role should remain one of nonjudgemental interest, with a clear commitment to help the patient through difficult times. The role of prayers, spiritual healing and fasting needs to be recognised and accepted for a successful outcome of any therapeutic intervention from the psychiatrist.

\section{The psychiatric services}

On the whole psychiatric services do not cater enough for ethnic minorities. The problem starts from a mixed ward, where Muslim women especially find it difficult to adjust and have privacy. There is little attention paid to the religious and cultural needs of the individual patient, including food and prayer times. Staff on the ward are rarely educated about the background of the patients or have knowledge of the country of origin and the cultural issues that may help them to evolve a more therapeutic intervention. This problem spreads to the day services, psychological services and community services, where the facilities are less than satisfactory.

\section{Conclusion}

We have attempted to outline the more important practical issues, which have important implications in psychiatric practice, when a patient is referred. All members of the multidisciplinary mental health team practising with ethnic minorities need to widen their knowledge about the background of a particular group of patients, and to be able to provide the best possible service.

\section{Acknowledgement}

We thank Dr Martin Davis, Consultant Psychiatrist, Queen Elizabeth Psychiatric Hospital, for his valuable comments on the paper

\section{References}

LTHEWOOD, R. \& LIPSEDGE, M. (1989) Allens and Allenists: Ethnic Minorttes and Psychiatry. London: Unwin Hyman. SHEIKH, A.J. \& GUEST, D. (1991) Psychiatric and marital morbidity in mixed race couples - a postal survey. British Journal of Clinical and Soctal Psychiatry. 8.

A. Jawad Sheikh, Consultant Psychiatrist; and Saeed Farooq, Registrar, The Bruce Burns Centre, Solihull Hospital, Lode Lane, Solthull, West Midlands B91 $2 \mathrm{JL}$ 